\title{
Clinton administration urges basic research boost in new budget plans
}

Washington. The Clinton administration has told all agencies and government departments with a responsibility for research to boost spending on basic science in their budget requests for the 1996 financial year, which starts on 1 October 1995.

The White House instruction is contained in an unpublished memorandum from Leon Panetta, director of the Office of Management and Budget (OMB), and Jack Gibbons, director of the Office of Science and Technology Policy (OSTP), to all agency and department heads.

It confounds early expectations that the administration would favour technology over fundamental science in allocating its annual \$73-billion research and development (R\&D) budget. The memorandum also tells agencies and departments to increase the amount of R\&D money going to the universities, and to subject more of their spending to thorough peer review.

Panetta and Gibbons do not specify where the extra money will come from. But the growth is likely to be at the expense of intramural government $R \& D$. The largest such programmes are those at the Department of Energy, the Department of Defense (DoD) and the National Aeronautics and
Space Administration (NASA).

The 18-page memorandum outlines the "R\&D broad policy principles, goals, priorities and evaluation criteria" for all agencies as they prepare budget submissions for the 1996 fiscal year. It is based on work carried out by the nine subpanels of the National Science and Technology Council (NSTC) which President Clinton established last November (see Nature 366, 393; 1993). Its suggestions on basic research appear to reflect the impact of the fundamental science and engineering subpanel, which has acted quickly to build a case for basic science.

"Agencies are strongly encouraged to measurably increase their absolute investment in (1) fundamental (basic) research and (2) research supported in academic institutions in the FY96 budget submissions," Gibbons and Panetta say in the memorandum. "In addition, merit reviewed with peer evaluation research, especially that research conducted at academic institutions, is of highest priority. Thus, research not subjected to peer review is expected to decline."

They identify six target areas "needing new or additional emphasis in FY 96". These are: a healthy, educated citizenry; job creation and economic growth; [US] world lead-

\section{Hubble reveals 'proof' of black hole}

Washington. Almost everything in astronomy is uncertain to within a factor of 2. But even allowing for that uncertainty, there was general acceptance among astronomers last week that Holland Ford and his collaborators at the Space Science Institute in Baltimore, Maryland, have demonstrated the existence of a giant black hole at the centre of the galaxy M87.

By using the Hubble Space Telescope to measure the Doppler shift of emission lines from doubly ionized oxygen about 20 parsecs (65 light years) away from the centre (see above), the astronomers have determined a rotation velocity of about $550 \mathrm{~km}$ per second for the gas, and estimated a mass interior to that point of 2-3 $\times 10^{9}$ solar masses.

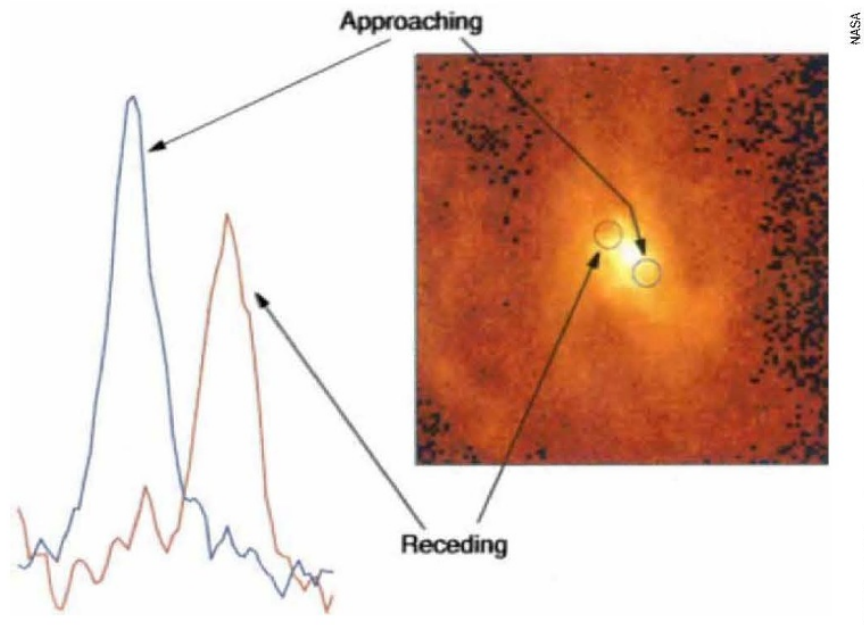

The mass in this small region is so great that is very hard to conceive of any explanation other than a giant black hole. If the mass were contained in stars like the Sun, they would be packed 75,000 times more densely than in the solar neighbourhood. But this explanation is very unlikely, as there is not enough light coming from this region to allow the presence of so many stars.
Leslie Sage ership in science, maths and engineering; improved environmental quality; harnessing information technology; and enhanced national security.

In each case, fairly detailed priorities are listed for extra government investment. On health, for example, the memorandum singles out vaccine development for AIDS and other diseases, methods for preventing HIV transmission and a range of nutritional, environmental and social approaches to the improvement of public health.

Genetics, structural biology and neuroscience are all emphasized. But the health section has a 'back-to-basics' tone, with less emphasis on high-tech medicine and more on meeting the health needs of America's poor.

On the issue of economic growth, Panetta and Gibbons ask for further expansion of a number of industrial programmes already initiated, including the Advanced Technology Program. But a notable omission from the goals for aeronautics are the plans of Daniel Goldin, head of NASA, for R\&D on supersonic civil aircraft.

As well as promising to expand basic research funding, Panetta and Gibbons pledge to start "an interagency program of competitive awards" to fund new university buildings and equipment in 1996.

Among many environmental issues raised, there are specific pledges to launch large-scale pilot studies in 1996 to test integrated ecosystem management, and to initiate "demonstration projects to determine the feasibility of biomass as a major energy supply technology". Predictably enough, the information technology section emphasizes applications and means of access for the information superhighway.

The section on national security is short on specifics, beyond the need for better intelligence gathering and work "to make land mines self-neutralizing after a compressed period of time". This suggests either that the DoD has plenty of secret projects in hand, or that it is having trouble justifying its $\$ 40$-billion share of the annual research and development budget.

Alternatively, the DoD may think it has better things to do than explaining itself to the NSTC - a body that has yet to prove its authority. The congressional warlords who traditionally carve up the science budget were always expected to resist any encroachment by Gibbons and the NSTC on their turf (see Nature 365, 195; 1993). But Panetta is a powerful figure in Washington, and this assertive and purposeful memorandum is a clear sign that the NSTC means business. 